\title{
Middle hepatic vein incorporation in live donor liver graft transplantation; implication and safety
}

\author{
Mahmoud Ali Abdi \\ College of Medicine, University of Zakho, \\ Fellow at Kurdistan Board for Medical \\ Specialization in Digestive Surgery, MBChB, \\ FKBMS, Zheen International Hospital, Erbil, \\ Kurdistan Region, Iraq \\ Email: mahmoud.abdi@uoz.edu.krd
}

\author{
Tayeb Sabir Kareem \\ Department of surgery, Hawler Medical \\ University, Department of Digestive \\ Surgery, Kurdistan Board for Medical \\ Specialization, FIBMS, FRCS, FACS, \\ Rizgary Teaching Hospital, Erbil, \\ Kurdistan Region, Iraq \\ Email: tayebsk@yahoo.com
}

Assad Abidon Hassoun

Department of Digestive Surgery, Kurdistan Board for Medical Specialization, General surgery \& organ transplant surgeon, MD, FACS, CPMC San Francisco, CA 94115, Zheen International Hospital, Erbil, Kurdistan Region, Iraq

Email: assadhassoun@yahoo.com
Article Info

Volume 6 - Issue 1- June 2021

DOI:

10.24017/science.2021.1.14

Article history:

Received 11/7/2021

Accepted 28/7/2021

\section{Keywords:}

LDLT, MHV, Donor safety, Doppler US, Venous outflow, liver transplant

\begin{abstract}
Background: In this retrospective study, the middle hepatic vein (MHV)was used in live donor liver transplantation, and the venous outflow dynamics were studied immediately after transplant meanwhile we studied the impact of the graft function on donor functionality and overall donor safety.

Method: from October 2017 to October 2020, 40 adults to adults live donor liver transplants were performed at our center. Postoperative Doppler ultrasound was performed for recipients and donors immediately after surgery and then daily until discharge.

Results: Mean donor age was $(28.5 \pm 6.9)$ year, male/ female 19/ 21 , intensive care unit stay $(1.2 \pm 0.43)$, word stay $(5.2 \pm 1.4)$ days, portal vein velocity $(43.5 \pm 18.4 \mathrm{ml} / \mathrm{sec})$, hepatic artery resistive index $(0.6 \pm 0.09)$ and triphasic/ continuous venous outflow $30 / 10$, postoperative day one and at the discharge total serum bilirubin was $(2.8 \pm 1.8)$ and $(2 \pm 1.4)$, postoperative day one and at the discharge international normalization ratio was $(1.7 \pm 0.5)$ and $(1.2 \pm 0.2)$ respectively. Mean recipient age was $(48.5 \pm 11.3)$, male/female $27 / 13$, intensive care unit stay $(4.75 \pm 3.9)$, word stay (7.7 \pm 3.7$)$ days, portal vein velocity $(63.96 \pm 24.65 \mathrm{ml} / \mathrm{sec})$, hepatic artery peak systolic velocity $(74.76 \pm 32.85)$ hepatic artery resistive
\end{abstract}


index $(0.7 \pm 0.15)$, and triphasic/continuous venous outflow 27/13.

Conclusion: Middle hepatic vein incorporation in live donor liver graft is safe with a favorable outcome for recipient and donor, doppler US is an important tool for evaluation and follow up of donor and recipient for detection of vascular complications and assessment of venous outflow. In addition, early discharge of the donor is a reasonable option.

Copyright () 2021 Kurdistan Journal of Applied Research. All rights reserved.

\section{INTRODUCTION}

Live donor liver transplant (LDLT) is challenged with small for size syndrome, which is an impairment of liver graft function especially during the first post-operative week, that is related to either the graft size or the graft parenchymal quality or the recipient portal hypertension and other medical comorbidities such as hypertension [1-4]

portal pressure shear injury, as well as decrease the impedance to the arterial inflow. [5-7]

Using the right liver lobe and because of higher parenchymal volume would mitigate these injuries but donor safety has always been questioned when MHV is incorporated. [8-10]

Doppler US can be used postoperatively for the detection of vascular complications in liver transplants. [11]

In this retrospective study, the middle hepatic vein was used in live donor liver transplantation and the venous outflow dynamics was studied immediately after transplant meanwhile we studied the impact of the graft function on donor functionality and overall donor safety.

\section{METHODS AND MATERIALS}

\subsection{Study design and patient selection}

From October 2017 to October 2020, 40 donor-related adult to adult LDLT was performed in our center. The data was collected retrospectively from the patient's recorded files that were stored in the hospital. The institutional review board approved this study.

\subsection{Donor evaluation}

Only adult to adult right lobe LDLT was included in this study, the donors were evaluated for overall health status, ABO incompatibility, CMV, EBV, Liver size, parenchymal texture, steatosis, the anatomy of hepatic arteries and venous system, and the anatomy of the biliary tree by history, physical exam, lab tests, doppler US, Quad phasic CT of the abdomen (Figure 1) and MRCP.
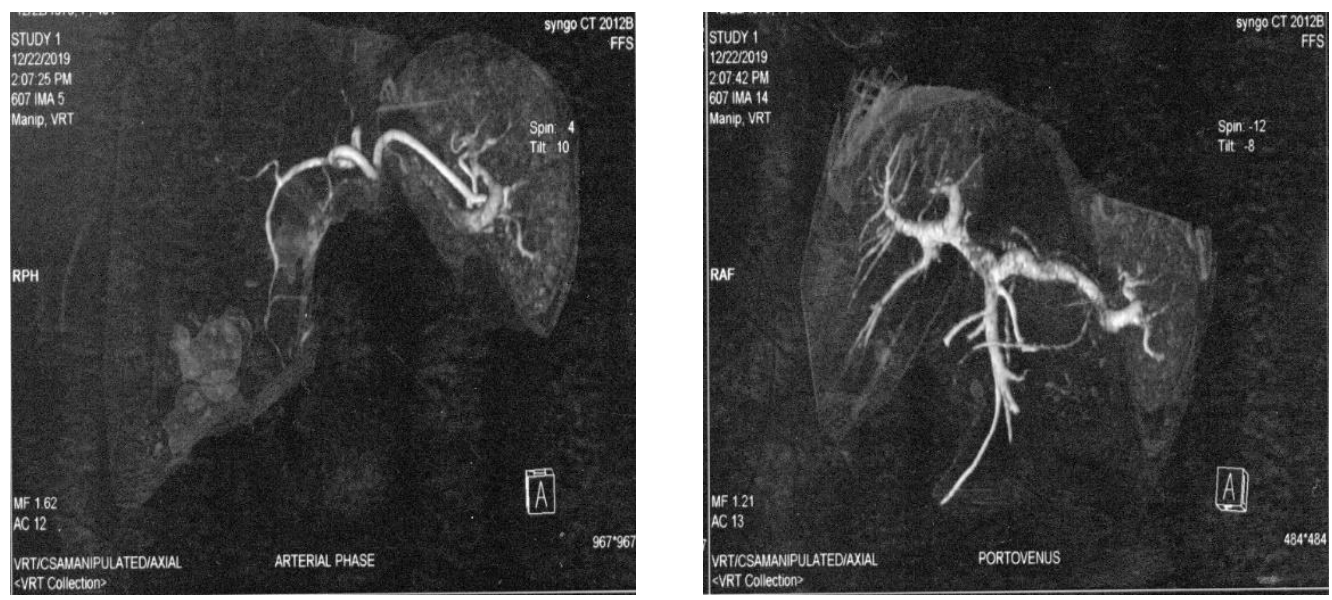


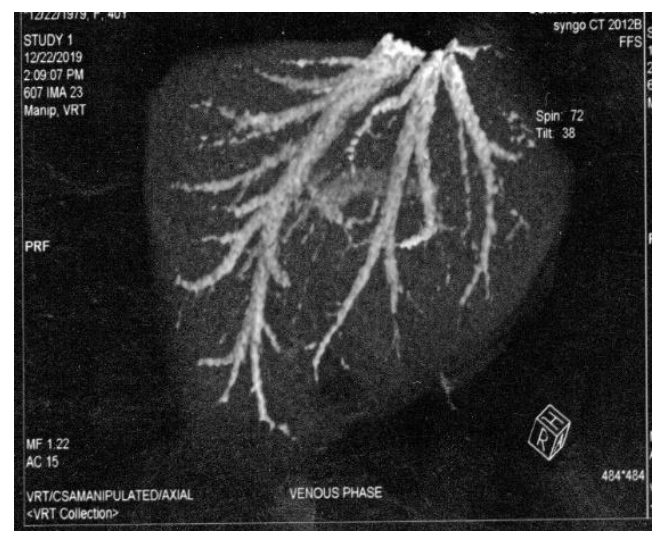

(C)

Figure1. Quad phasic CT of Liver, (A) arterial phase showing hepatic arteries, (B) portal vein phase showing portal veins, and $(C)$ venous phase showing hepatic veins.

\subsection{Surgical procedure}

Partial right hepatectomy including MHV was performed for donors after intraoperative cholangiogram (Figure2) and doppler US to evaluate the biliary tree and HV anatomy respectively. On table reconstruction of hepatic veins was done using recipient portal vein segment and forming a single orifice.

The right grafted lobe of the liver was transplanted to the recipient after reconstruction of hepatic veins.

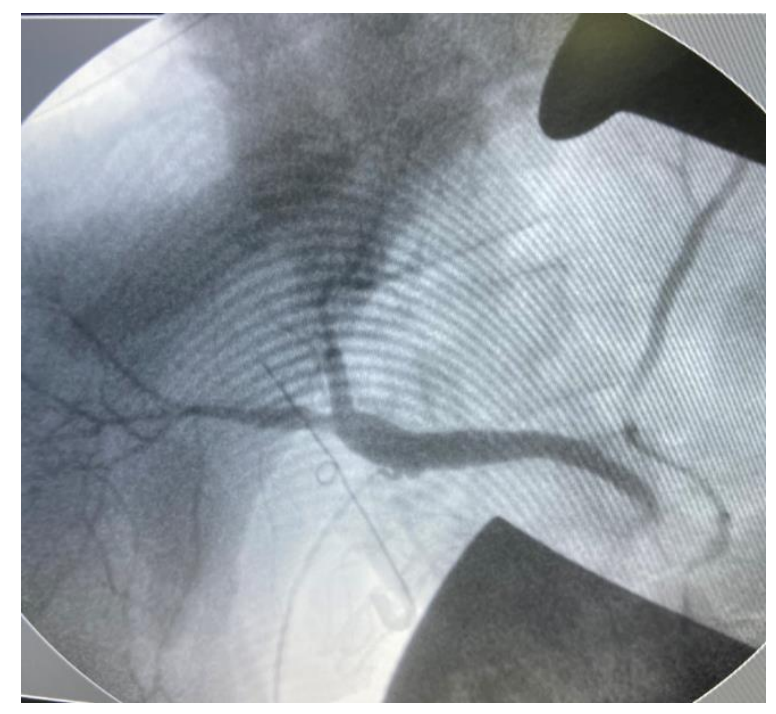

Figure 2. Intraoperative cholangiogram showing a biliary tree.

\subsection{Postoperative Doppler US}

Postoperative Doppler US was performed for recipients and donors immediately after surgery then daily until discharge. The Doppler US has been performed by an expert radiologist in liver transplant doppler US. The Doppler US was performed in a supine or semi-setting position using a curvilinear transducer of low frequency $(2-5 \mathrm{MHz})$, the HA and PV were examined 
extrahepatically and across the anastomosis, the parameters of flow and velocity of PV and PSV and RI of HA were recorded. The intrahepatic branches of HA were also examined for patency. The HV and IVC were examined and the parameters of HV flow and wave-trace were recorded. The US of abdomen and liver was performed to evaluate for liver parenchyma, fluid collection or ascites.

The highest recorded value of PV velocity, PSV, and RI of HA was chosen from recoded parameters of PV, HA through day Zero postoperative until discharge. The hepatic vein flow and wave trace were categorized as a triphasic or continuous flow.

\subsection{Post-operative lab values}

As a part of the evaluation of the donor's liver functionality post-donation, we calculated postoperative day one and at discharge TSB and INR.

\subsection{Statistical Analysis}

Descriptive analysis for data was performed using SPSS version 25, means with standard deviations and range were expressed for PV velocity, PSV, and RI of HA, and HV velocity. Post-operative day one (POD 1) and at discharge TSB and post-operative day one and the discharge INR for the donor. categorical variables were analyzed using the chi-square test or Fisher's test if necessary. Continuous and discrete variables were analyzed using a t-test. Means were compared for triphasic versus continuous hepatic venous outflow wave signals using the One-Way ANOVA test. Differences at P less than .05 were considered significant.

\section{RESULTS}

The demographic characteristics, lab values, and doppler US parameters including PV velocity, HA PSV, and RI and HV waveform for donors and recipients are summarized in (table 1 and table 2) respectively.

Mean donor's age was $(28.5 \pm 6.9)$ range (18-42) year, they were 19 males and 21 females, mean ICU stay was $(1.3 \pm 0.9)$ range (1-4) days and mean word stay before discharge was (5.2 \pm 1.4$)$ range (3-9) days, their mean PV velocity was $(43.5 \pm 18.4 \mathrm{ml} / \mathrm{sec})$ range $(17-91.60 \mathrm{ml} / \mathrm{sec})$ and mean HA RI was $(0.6 \pm 0.09)$ range $(0.43-0.78)$.

Table 1. The demographic characteristics and Doppler US parameters for donors

\begin{tabular}{ll}
\hline Donor & $\mathbf{N}(\mathbf{4 0})$ \\
\hline Age (year) & $28.5 \pm 6.9$ \\
& Range (18-42) \\
\hline Gender (M/F) & $19 / 21$ \\
\hline ICU stay (days) & $1.2 \pm 0.4$ \\
& Range (1-3) \\
\hline Word stay(days) & $5.2 \pm 1.4$ \\
& Range (3-9) \\
\hline PV velocity (cm/sec) & $43.5 \pm 18.4$ \\
& Range (17-91.6) \\
\hline HA RI & $0.6 \pm 0.09$ \\
& Range (0.4-0.8) \\
\hline HV waveform (triphasic/ continuous) & $30 / 10$ \\
\hline
\end{tabular}




\begin{tabular}{lll}
\hline TSB & POD 1 & $2.8 \pm 1.8$ range $(0.4-8)$ \\
& At discharge & $2 \pm 1.4$ range $(0.2-5.7)$ \\
& & \\
\hline INR & POD 1 & $1.7 \pm 0.5$ range $(1-2.8)$ \\
& At discharge & $1.2 \pm 0.2$ range $(0.9-2.2)$ \\
\hline
\end{tabular}

Table 2. The demographic characteristics and Doppler US parameters for recipients

\begin{tabular}{ll}
\hline Recipient & $\mathrm{N}(40)$ \\
\hline Age (year) & $48.5 \pm 11.3$ \\
& Range $(19-67)$ \\
\hline Gender (M/F) & $27 / 13$ \\
\hline ICU stay (days) & $4.75 \pm 3.9$ \\
& Range $(2-20)$ \\
\hline Word stay(days) & $7.7 \pm 3.7$ \\
\hline PV velocity (cm/sec) & Range $(3-22)$ \\
\hline HA PSV (cm/sec) & $63.96 \pm 24.65$ \\
& Range $(21-115)$ \\
\hline HA RI & $74.76 \pm 32.85$ \\
& Range $(32-153)$ \\
\hline HV waveform (triphasic/ continuous) & $0.7 \pm 0.15$ \\
\hline
\end{tabular}

Thirty of the donor had triphasic venous outflow wave signals and 10 of them had continuous venous outflow wave signals, their mean POD 1 TSB was $(2.8 \pm 1.8)$ range $(0.40-8)$, mean discharge TSB was $(2 \pm 1.4)$ range $(0.24-5.7)$, mean POD 1 INR was $(1.7 \pm 0.5)$ range $(1.1-2.8)$ and mean discharge INR was $(1.2 \pm 0.23)$ range $(0.9-2.2)$ when compared means for (triphasic vs continuous) venous outflow waveform group, there was no statistically significant difference in ICU stays and word stays between two groups (Table 3).

Table 3. compered means for (triphasic vs continuous) venous outflow waveform donor groups

\begin{tabular}{llccc}
\hline & HV waveform & N (40) & Mean \pm SD & P-value \\
\hline ICU stay (days) & Continuous & 10 & $1.30 \pm 0.95$ & 0.92 \\
\cline { 2 - 4 } & Triphasic & 30 & $1.33 \pm 0.85$ & 0.23 \\
\hline Word stay (days) & Continuous & 10 & $4.7 \pm 1.05$ & \\
\cline { 2 - 4 } & Triphasic & 30 & $5.3 \pm 1.5$ &
\end{tabular}

Regarding donor functionality and donor safety. One donor has taken back to the OR on a postoperative day two for bleeding washout, one donor readmission for two days for pain, one donor developed small-for-size syndrome and completely recovered after two months follow up and one donor developed bile leak that warranted an ERCP stenting and sphincteroplasty. No donor mortality, and no intervention required for any donor within the period of the study. 
Mean recipient's age was $(48.5 \pm 11.3)$ range (19-67) year, they were 27 males and 13 females, mean ICU stay was $(4.75 \pm 3.9)$ range $(2-20)$ days and mean word stay before discharge was $(7.7 \pm 3.7)$ range $(3-22)$ days, their mean PV velocity was $(63.96 \pm 24.65 \mathrm{ml} / \mathrm{sec})$ range $(21-115$ $\mathrm{ml} / \mathrm{sec})$, mean HA PSV was $(74.76 \pm 32.85)$ range $(32-153)$ and their mean HA RI was $(0.7 \pm$ $0.15)$ range $(0.41-1)$. 27 of of the recipient had triphasic venous outflow wave signals and 13 of them had continuous venous outflow wave signals, again when compared means for (triphasic vs continuous) venous outflow waveform group, there was no statistically significant difference in ICU stays and word stays between the two groups (Table 4).

Table 4. compered means for (triphasic vs continuous) venous outflow waveform recipient groups

\begin{tabular}{llccc}
\hline & HV waveform & N (40) & Mean \pm SD & P-value \\
\hline ICU stay (days) & Continuous & 13 & $5.5 \pm 4.2$ & 0.38 \\
\cline { 2 - 5 } & Triphasic & 27 & $4.4 \pm 3.8$ & \\
\hline Word stay (days) & Continuous & 13 & $8 \pm 4.6$ & 0.74 \\
\cline { 2 - 5 } & Triphasic & 27 & $7.6 \pm 3.2$ & \\
\hline
\end{tabular}

Regarding recipient morbidity and mortality. Two recipients were taken back to OR for bleeding washout, one in POD 4 and the other in POD 6. Two recipients developed transient renal failure, one required CRRT for 3 days and the other for 2 days.

Four recipients died, one died intraoperatively from cardiogenic shock and acute myocardial infarction. Two of the recipients died from sepsis in POD 5 and POD 7 respectively, and one died from DIC in POD1.

\section{DISCUSSION}

Donor safety, remnant liver volume for the donor, and graft volume for the recipient are the major concerns and dilemmas for living donor liver transplant however published studies showed favorable results and minor concerns. [8-10]

Lee JG et al. published a study from Korea, they performed living donor liver transplant without MHV in the majority of their cases and showed that donor hepatectomy can be performed successfully with minor morbidity and easily controlled complications, the biliary complications were the most common major complication, they didn't find a statistical difference in laboratory results or complication between the donor with RLV less than $30 \%$ and those with RLV of more than $30 \%$. [12]

In this study, we had one donor with a major biliary leak. He was a young male donor the amount of bile leak was about $500 \mathrm{ml}$ per day which was treated by an ERCP, one donor developed small for size syndrome in form of persistent hyperbilirubinemia, ascites, and mild elevation of liver enzymes but no coagulopathy or encephalopathy. [1]

The donor was female with borderline liver size and overweight with a BMI of 30, we selected her because she was the only available donor for the recipient and transplantation was urgent, she had one day ICU stay and discharged at postoperative day10th, follow up showed complete recovery after two months with no major complications.

Although we didn't interpret the donor RLV in this study, however, we relayed on postoperative TSB and INR as a reflector for donor RLV and liver function, and we studied the Doppler US parameters for the donor liver immediately postoperative until discharge for evaluation of donor RL venous outflow dynamics and detection of vascular complications. We found a significant decrease in both TSB and INR in discharge day compared to POD1 and one-month follow-up showed normalization of both TSB and INR. In addition, the Doppler US parameters for the 
donor RL showed favorable results. Although there was an increase in PV and a decrease in HAIR, and one quarter (10/40) had continuous venous outflow wave signals, however, there were no signs of liver congestion or any vascular complications and these changes were transient, one month follow up showed normalization of all of these changes.

When incorporating the middle hepatic vein in the right lobe liver graft will mitigate graft congestion especially in segment V and VIII and will give a better graft function, however, it didn't make a statistical difference regarding the recipient ICU and hospital stay, in Dayangac $\mathrm{M}$ et al. study the recipient hospital stay was $21.7 \pm 14.2$ vs $21.6 \pm 10.9$ (days) and the donor hospital stay was $10.2 \pm 3.2$ vs $9.7 \pm 2.6$. In Goja S et al. study the recipient ICU stay was $5.8 \pm$ 2.2 vs $5.9 \pm 2.3$ (days) and their hospital stay was $15.8 \pm 6.5$ vs $16.1 \pm 7.2$ (days), and the donor hospital stay was $6(5-22)$ vs 6 (5-17) days for a group with MHV vs without MHV respectively. $\{10,13\}$

Comparing these results with the current study, this study showed more favorable results, the recipient ICU stay was $4.75 \pm 3.9$ (days) and their hospital stay was $12.5 \pm 6.32$ (days) and the donor hospital stay was 6 (4-9) days with MHV.

Immediate postoperative and then daily doppler US is a reliable tool for evaluation of recipient's liver graft and donor RL venous outflow dynamics and vascular complications and it decreases the need for more invasive CT angiography as far as there are no concerns about liver functions and there is no persistent increase in PV velocity and HA RI.

Although there were 10 recipients with HA RI of more than 0.8 and three recipients with HA RI of less than 0.55 which normally ranges from $(0.55$ to 0.8$) .\{11\}$ However, these changes in PV velocity and HA RI were transient and normalized after follow-up.

We usually discharge donors before the normalization of their RL function including TSB and INR as far as the donor has no other concerns and we follow them weekly until liver function becomes normal and it reached normal after one-month follow-up. These mostly explain the reasons behind our shorter hospital stays for recipients and donors.

\section{CONCLUSION}

Middle hepatic vein incorporation in live donor liver graft is safe with a favorable outcome for recipient and donor, doppler US is one the important tool for evaluation and follow up of donor and recipient for detection of vascular complications and assessment of venous outflow. In addition, early discharge of the donor is a reasonable option.

\section{ETHICAL APPROVAL}

This study was approved by the Ethics Committee of the Kurdistan Board of Medical Specialization and was conducted in accordance with the provisions of the declaration of Helsinki.

\section{ACKNOWLEDGMENTS}

Special thanks to Senior radiologist Dr. Yousif Badria for his outstanding cooperation and work on Doppler ultrasound.

\section{GRANTS AND FINANCIAL SUPPORT}

No funding was received from any sources.

\section{COMPETING INTEREST}

No competing interest 


\section{AUTHORS CONTRIBUTIONS}

Mahmoud Abdi: Data curation, Writing- Original draft preparation, Software, Formal analysis. Tayeb Kareem: Supervision, Validation. Assad Hassoun: Supervision, Conceptualization, Methodology, Writing - Review \& Editing.

\section{LIMITATIONS OF THIS STUDY}

- The sample size is small and we didn't include left lobe graft in this study

- We didn't study the results of long-term follow-up for recipients.

- The assessment of operative factors and intraoperative parameters has not been considered in this study and further studies need to be done to evaluate all those limitations.

\section{ALPHABETIC ABBREVIATIONS}

$\mathrm{BMI}=$ body mass index

$\mathrm{CMV}=$ cytomegalovirus

$\mathrm{CT}=$ computed tomography

$\mathrm{CRRT}=$ continuous renal replacement therapy

$\mathrm{DIC}=$ disseminated intravascular coagulation

$\mathrm{EBV}=$ Epstein-barr virus

$\mathrm{ERCP}=$ endoscopic retrograde cholangiopancreatography

$\mathrm{HA}=$ hepatic artery

$\mathrm{HV}=$ hepatic vein

$\mathrm{ICU}=$ intensive care unit

$\mathrm{INR}=$ international moralization ratio

LDLT $=$ live donor liver transplant

$\mathrm{MHV}=$ middle hepatic vein

$\mathrm{MRCP}=$ magnetic resonance cholangiopancreatography

$\mathrm{OR}=$ operation room

$\mathrm{POD}=$ post-operative day

$\mathrm{PSV}=$ peak systolic velocity

$\mathrm{PV}=$ portal vein

$\mathrm{RI}=$ resistive index

$\mathrm{RL}=$ remnant liver

RLV = remnant liver volume

$\mathrm{TSB}=$ total serum bilirubin

$\mathrm{US}=$ ultrasound 


\section{REFERENCES}

[1] F. Dahm, P. Georgiev, P. C.-A. J. Of, and U. 2005, "Small-for-size syndrome after partial liver transplantation: definition, mechanisms of disease and clinical implications," Wiley Online Libr., Accessed: Sep. 12, 2020. [Online]. Available: https://onlinelibrary.wiley.com/doi/abs/10.1111/j.16006143.2005.01081.x.

[2] C. H. N. Tan, S. Hwang, G. K. Bonney, I. S. Ganpathi, K. Madhavan, and W. C. A. Kow, "The influence of the middle hepatic vein and its impact on outcomes in right lobe living donor liver transplantation," $H p b$, vol. 21, no. 5, pp. 547-556, 2019, doi: 10.1016/j.hpb.2018.09.003.

[3] T. Ito et al., "Changes in portal venous pressure in the early phase after living-donor liver transplantation: Pathogenesis and clinical implications," Transplantation, vol. 75, no. 8, pp. 1313-1317, 2003, doi: 10.1097/01.TP.0000063707.90525.10.

[4] S. H. Kim, E. C. Lee, J. R. Shim, and S. J. Park, "Right lobe living donors ages 55 years old and older in liver transplantation," Liver Transplant., vol. 23, no. 10, pp. 1305-1311, 2017, doi: 10.1002/lt.24823.

[5] S. K. G. Lee et al., "Anterior segment congestion of a right liver lobe graft in living-donor liver transplantation and strategy to prevent congestion," J. Hepatobiliary. Pancreat. Surg., vol. 10, no. 1, pp. 16-25, 2003, doi: $10.1007 / \mathrm{s} 10534-002-0789-5$.

[6] M. Appukuttan et al., "Functional hepatic venous outflow and its correlation with early graft function in live donor liver transplantation," Hpb, vol. 18, p. e556, 2016, doi: 10.1016/j.hpb.2016.03.485.

[7] H. R. Yang et al., "Living donor right hepatectomy with inclusion of the middle hepatic vein: Outcome in 200 donors," Transplant. Proc., vol. 44, no. 2, pp. 460-462, 2012, doi: 10.1016/j.transproceed.2012.01.060.

[8] T. Ikegami, S. Onda, K. Furukawa, K. Haruki, Y. Shirai, and T. Gocho, Small-for-size graft, small-for-size syndrome and inflow modulation in living donor liver transplantation, vol. 27, no. 11. 2020.

[9] X. Z. Jiang et al., "Safety of Donor in Adult-to-Adult Living Donor Liver Transplantation Using Right Lobe Graft,” Transplant. Proc., vol. 39, no. 1, pp. 150-152, 2007, doi: 10.1016/j.transproceed.2006.10.013.

[10] M. Dayangac et al., "Use of middle hepatic vein in right lobe living donor liver transplantation," Transpl. Int., vol. 23, no. 3, pp. 285-291, 2010, doi: 10.1111/j.1432-2277.2009.00978.x.

[11] O. Abdelaziz and H. Attia, “2016 Liver Transplantation: Global view Doppler ultrasonography in living donor liver transplantation recipients : Intra- and post-operative vascular complications," vol. 22, no. 27, pp. 6145-6172, 2016, doi: 10.3748/wjg.v22.i27.6145.

[12] J. G. Lee et al., "Donor safety in living donor liver transplantation: The Korean organ transplantation registry study," Liver Transplant., vol. 23, no. 8, pp. 999-1006, 2017, doi: 10.1002/1t.24778.

[13] S. Goja, S. Kumar Yadav, and A. Singh Soin, "Readdressing the Middle Hepatic Vein in Right Lobe Liver Donation: Triangle of Safety," Liver Transplant., vol. 24, no. 10, pp. 1363-1376, 2018, doi: 10.1002/lt.25289. 